\title{
Análise dos marcos legais da gestão democrática nas escolas públicas estaduais da Bahia
}

\author{
Edna Santos de Jesus ${ }^{1}$ \\ https://orcid.org/0000-0001-8917-8945 \\ Mary Adriana dos Santos Evangelista ${ }^{2}$ \\ https://orcid.org/0000-0002-4143-0942 \\ Rodrigo da Silva Pereira ${ }^{3}$ \\ https://orcid.org/0000-0003-0371-3789
}

\section{Resumo}

O presente trabalho objetiva analisar os marcos legais da política de gestão democrática nas escolas públicas estaduais baianas, buscando evidenciar os possíveis avanços e lacunas na legislação vigente e as contradições dessa política com os princípios da Nova Gestão Pública (NGP). Este artigo conclui que é imprescindível o estabelecimento legal de ações permanentes de fortalecimento das instâncias que norteiam e asseguram a política de gestão democrática nas escolas públicas e que a educação baiana conta com marcos legais considerados avançados para democratização das unidades escolares. Porém, os princípios e práticas adotadas a partir do referencial político e epistemológico da NGP acabam por comprometer iniciativas que busquem dar materialidade ao que está subscrito no marco legal.

Palavras-chave: Política Educacional. Gestão Democrática. Legislação. Nova Gestão Pública; Bahia.

\begin{abstract}
This paper aims to analyze the legal frameworks of democratic management policy in the state public schools of Bahia, seeking evidence of possible advances and gaps in current legislation and as contradictions of this policy with the principles of New Public Administration (NGP). This article concludes that it is essential the legal establishment of permanent actions to strengthen the instances that guide and ensure the democratic management policy in public schools and that Bahian education has legal frameworks considered advanced for democratization of school units. Contradictorily, the principles and practices adopted from the political and epistemological framework of the NGP end up compromising initiatives that seek to give materiality to what is subscribed in the legal framework.
\end{abstract}

Keywords: Educational Politics. Democratic Management. Legislation. New Public Management. Bahia.

\footnotetext{
Mestranda do Programa de Pós-graduação em Educação, na Linha de Políticas e Gestão da Educação - Universidade Federal da Bahia (UFBA). E-mail: edna-marone@hotmail.com

${ }^{2}$ Mestranda do Programa de Pós-graduação em Educação, na Linha de Políticas e Gestão da Educação - UFBA. E-mail: maryadriana.evangelista@gmail.com

3 Professor na Faculdade de Educação da Universidade Federal da Bahia (FACED/UFBA). Vice-coordenador do Programa de Pós-Graduação em Educação (PPGE/FACED/UFBA), na linha de pesquisa Políticas e Gestão da Educação. Doutor e Mestre em Políticas Públicas e Gestão da Educação pelo Programa de Pós-Graduação da Faculdade de Educação da Universidade de Brasília. E-mail: rodrigosilvapereira@ufba.br
} 


\section{Introdução}

Este trabalho é parte de pesquisa em andamento sobre a gestão nas unidades escolares de ensino médio da cidade de Salvador - BA e região metropolitana - Núcleo Territorial de Educação (NTE-26), desenvolvido pelo Grupo de Estudos e Pesquisas em Política Educacional (GEPPOLE) da Linha de Pesquisa em Políticas e Gestão da Educação do Programa de Pós-Graduação em Educação da Universidade Federal da Bahia - UFBA. Objetiva analisar os marcos legais da política de gestão democrática nas escolas públicas estaduais baianas, buscando evidenciar os possíveis avanços e lacunas na legislação vigente e as contradições dessa política com os princípios da Nova Gestão Pública (NGP)

De acordo com Dourado (2006), nas últimas décadas, vivenciamos um processo de aceleração dos avanços tecnológicos, da globalização do capital e das transformações nas relações de trabalho que trouxeram mudanças para as políticas de gestão e de regulação da educação brasileira e essas mudanças interferem na organização da escola e nos papéis dos diversos atores sociais que constroem seu cotidiano.

Nessa ótica, compreender esse processo e a legislação dele decorrente, bem como, garantir a materialidade dessas discussões e deliberações no interior da escola, é um desafio que se coloca para todos que lutam por uma escola pública melhor e comprometida com a mudança social.

\footnotetext{
Uma lei que trate da democracia tem que se pretender democrática. [...] A disposição ao diálogo entre esses sujeitos é determinante na qualidade da peça legal e potencialmente contribuirá para a ampliação das chances do seu cumprimento (SOUZA; PIRES, 2018; p. 81).
}

A discussão sobre a gestão escolar, na perspectiva de gestão democrática, é presença constante nas agendas internacionais e nacionais de políticas públicas educacionais. Na definição de Souza (2009, p. 125-126):

\footnotetext{
A gestão democrática é compreendida então como um processo político no qual as pessoas que atuam na/sobre a escola/educação identificam problemas, discutem, deliberam e planejam, encaminham, acompanham, controlam e avaliam o conjunto das ações voltadas ao desenvolvimento da própria escola/sistema na busca da solução daqueles problemas. Esse processo, sustentado no diálogo, na alteridade e no reconhecimento às especificidades técnicas das diversas funções presentes na escola/sistema, tem como base a participação efetiva de todos os segmentos da comunidade escolar/ sociedade, o respeito às normas coletivamente construídas para os processos de tomada de decisões e a garantia de amplo acesso às informações aos sujeitos.
}

No Brasil, a gestão escolar tem sido temática de estudos e pesquisas, com maior ênfase, após a reabertura político-democrática, pós-Ditadura Militar (1964 - 1985), com a escolha dos representantes políticos via eleições diretas e a perspectiva de vivência de relações mais democráticas.

A Constituição Federal do Brasil (CF) de 1988, denominada de Constituição Cidadã, declara a educação como um direito social, "visando ao pleno desenvolvimento da pessoa, seu preparo para o exercício da cidadania e sua qualificação para o trabalho" (BRASIL, 1988, Art. 205). Estabelece, portanto, “a base da organização educacional do país ao firmar direitos e deveres, delimitar competências e atribuições, regular o financiamento e definir princípios como: pluralismo, liberdade e gestão democrática” (DOURADO, 2006, p. 39).

A respeito disso, Cury (2005, p. 15) reflete: 
Certamente, o pleno desenvolvimento da pessoa, marca da educação como dever de Estado e direito do cidadão, conforme o art.205 da mesma Constituição, ficará incompleto e truncado se tal princípio não se efetivar em práticas concretas nos sistemas e no chão da escola.

Práticas concretas também são demandadas na caminhada pela normatização do princípio da democracia na gestão da educação, consagrada no art. 206 da CF, destacando-se, então, pelo ineditismo do termo, em texto constitucional. A regulamentação da gestão democrática como princípio do ensino público na CF não é condição suficiente para sua prática efetiva no espaço escolar já que a democracia resulta de processos e lutas coletivas e não apenas de leis estabelecidas. Nesse sentido: “É razoável temer que, em um país com pouca solidez nas instituições e que ainda não experimentou a democracia de maneira ampla, tais indicações normativas não sirvam de garantia de implementação da gestão democrática da educação pública" (SOUZA; PIRES, 2018, p. 80).

A Lei de Diretrizes e Bases da Educação Nacional (LDB), publicada em 1996, estabeleceu e regulamentou as diretrizes gerais para a educação nos sistemas de ensino, tornando-se um passo decisivo na política de democratização da gestão escolar, já que reconheceu o princípio federativo e remeteu aos sistemas de ensino a definição das "normas de gestão democrática do ensino público na educação básica", ressalvando a garantia da “participação dos profissionais da educação na elaboração do projeto pedagógico da escola" e a "participação das comunidades escolares e local em conselhos escolares ou equivalentes" (BRASIL, 1996, Art. 14).

Nesse cenário, e seguindo o que foi preconizado pela LDB, o sistema de ensino público estadual da Bahia, que é constituído por 1.203 escolas com um total de 822.320 estudantes matriculados e distribuídos em unidades escolares de 416 municípios baianos (INEP 2018), anunciou o estabelecimento de normas de gestão democrática, através de leis e decretos, que normatizaram a implantação e o funcionamento de instâncias de participação da comunidade escolar e local como os colegiados e a implementação de eleições para escolha dos gestores.

Para construção deste artigo foi realizada uma análise dos documentos legais que tratam da gestão democrática do ensino público brasileiro e da legislação vigente da gestão democrática nas escolas públicas estaduais baianas. O texto está organizado em três seções, sendo esta introdução, a primeira. A segunda seção trata da análise dos marcos legais da gestão escolar democrática nas escolas públicas estaduais e as contradições geradas pelos princípios da NGP. Na terceira e última, apresentaremos os resultados dessa pesquisa e as considerações finais do estudo.

\section{Os marcos legais da gestão democrática nas escolas públicas estaduais da Bahia e os princípios da Nova Gestão Pública}

Entendemos que a gestão escolar democrática é aquela na qual se prioriza a participação do coletivo em todas as ações e tomadas de decisões no âmbito da escola, no processo de compartilhamento de poder e de responsabilidades.

\footnotetext{
Na gestão democrática, a educação é tarefa de todos, família, governo e sociedade, mas para que ocorra essa sintonia é necessária a participação de todos os segmentos que compõem o processo educacional, de um trabalho coletivo que busque ações concretas. Para que se efetive essa gestão democrática, faz-se necessário vivenciar, no dia-a-dia, incorporar ao cotidiano da escola e tornar essencial para a vida organizacional da escola, assim como é fundamental a presença do professor e do aluno (CURY; HORTA; BRITO, 1997, p. 27).
}

Compreendendo a legislação como um elemento que pode contribuir para o processo de democratização da gestão escolar, indagamos quais são os marcos legais baianos que apontam para esta perspectiva? 


\section{Eleição dos gestores escolares}

A gestão escolar pública sempre foi tratada como um campo de disputas políticas. A escolha da direção de uma escola sempre esteve submetida às decisões de lideranças político-partidárias, traço característico do patrimonialismo (MENDONÇA, 2001).

Em 2014, após três anos de tramitação, foi instituído o Plano Nacional da Educação (PNE), em cumprimento ao art. 214 da $\mathrm{CF}$ e ao art. $9^{\circ}$ da LDB, com vigência de dez anos. O PNE, resguardando os princípios constitucionais, apresenta as diretrizes e as vinte metas centrais para os grandes setores da educação e traz, entre outros temas, a formação dos professores e gestores da educação, bem como, as estratégias para efetivação da gestão democrática da educação básica.

A meta 19 do PNE que incide sobre a gestão democrática da educação preconiza:

[...] assegurar condições, no prazo de 2 (dois) anos, para a efetivação da gestão democrática da educação, associada a critérios técnicos de mérito e desempenho e a consulta pública à comunidade escolar, no âmbito das escolas públicas, prevendo recursos e apoio técnico da União para tanto (BRASIL, 2014).

Dentre as estratégias previstas nessa meta, estão descritas ações como: a participação da comunidade escolar; a autonomia pedagógica, financeira e administrativa; a aplicação de provas e critérios objetivos ao provimento do cargo de gestor escolar na rede pública.

A meta 19 do PNE apresenta progressos na consolidação da gestão democrática do ensino público, na medida que, regulamenta que a comunidade deverá ser consultada, publicamente, sobre quem irá gerir as atividades pedagógicas, administrativas, tecnológicas , financeiras e sociais da escola, no entanto, encharcada dos princípios da NGP, associa essa escolha a " critérios técnicos de mérito e desempenho" e prioriza o repasse de recursos somente para os municípios e estados que aderirem ao especificado na estratégia 1, da meta 19:

\footnotetext{
Priorizar o repasse de transferências voluntárias da União na área da educação para os entes federados que tenham aprovado legislação específica que regulamente a matéria na área de sua abrangência, respeitando-se a legislação nacional, e que considere, conjuntamente, para a nomeação dos diretores e diretoras de escola, critérios técnicos de mérito e desempenho, bem como a participação da comunidade escolar (BRASIL, 2014, p. 1).
}

Desse modo, a efetivação do princípio constitucional da gestão democrática escolar esbarra nas pressões e determinações promovidas pela política gerencialista que exige, cada vez mais, a incorporação de mecanismos de mercado nos instrumentos formais do Estado e, consequentemente, na condução da gestão pública.

Sobre a meta 19 do PNE, Peroni e Flores (2014, p. 186) apontam que:

\footnotetext{
Se por um lado, a consulta pública à comunidade escolar prevista na Meta 19 pode significar um avanço nos locais onde não há histórico de gestão democrática, seja na forma de lei própria, seja na forma da vivência de processos democráticos, por outro lado, cabe um alerta no sentido de que a associação de critérios técnicos de mérito e desempenho a essa consulta à comunidade restringe a própria efetividade deste princípio. Em nosso entendimento, esta redação tenta articular em um mesmo texto dois mecanismos de gestão que representam concepções diferentes e mesmo antagônicas de gestão, uma de matriz democrática e outra vinculada a modelos de viés gerencial, restando aos entes federados o desafio de implementar em conjunto critérios tão distintos.
} 
Nesse panorama, analisaremos a sistemática para investidura dos dirigentes escolares na rede estadual baiana de ensino, que é normatizada pelo Art. 18 da Lei no 8.261/2002 (Estatuto do Magistério Público do Ensino Fundamental e Médio do Estado da Bahia) e pelo Decreto $n^{\circ}$ 16.385/2015, que dispõem sobre os critérios e procedimentos do processo seletivo interno para o preenchimento dos cargos de Diretor e Vice-Diretor das unidades escolares.

O certame para a escolha dos diretores escolares e vice-diretores, seguindo os preceitos do PNE, tem caráter seletivo e eletivo, sendo realizado em duas etapas: avaliação de conhecimento em gestão escolar e a eleição pela comunidade escolar (BAHIA, 2015).

Em atendimento ao que é determinado pelo $\S 1^{\circ}$ do Art. $1^{\circ}$ do Decreto $\mathrm{n}^{\circ} 16.385 / 2015$, a avaliação de conhecimento visa aferir as competências e habilidades em gestão escolar nos aspectos administrativos, pedagógicos e financeiros (BAHIA, 2015, p. 1). Essa etapa é denominada, na legislação, de certificação.

$\mathrm{Na}$ abordagem descrita pela normativa do concurso para diretores e vice-diretores, entendemos que a intenção do governo estadual é de lançar mão da certificação como um instrumento de avaliação para estabelecer padrões de competências e mérito entre os candidatos ao cargo. Esse é um modelo de caráter seletivo oriundo do setor privado, portanto, reflete a adoção de gestão gerencial do sistema escolar pelo poder executivo baiano.

O item 3.1 do Edital de $n^{\circ} 1$ da SEC/BA, publicado em 29 de setembro de 2015, que regulamentou o último processo de certificação para provimento de vagas para os cargos de diretores e de vice-diretores das unidades escolares da rede estadual de ensino, pormenoriza a aplicação de uma prova objetiva, de caráter eliminatório e classificatório, para aferição de habilidades e conhecimentos nas áreas de Gestão Pedagógica (Gestão de Resultados Educacionais) Gestão Administrativa/Financeira (Gestão de Pessoas/ Gestão de Processos) e Legislação Educacional (BAHIA, 2015).

Há de se esclarecer que a formação administrativa e pedagógica do dirigente escolar é uma prática necessária para melhoria da qualidade do ensino público. O que se questiona, nesse estudo, é qual a intencionalidade que move essa diligência, na perspectiva da NGP?

$\mathrm{Na}$ análise de Alves $(2015$, p. 3),

[...] a gestão democrática de sistemas de ensino e de escolas vem sendo, paulatinamente, substituída pela gestão gerencial da educação por meio de legislações específicas e de programas de gestão que estão regulando novas relações na organização do trabalho na escola, tendo como centro do processo, a gestão.

Desse modo, os conceitos da meritocracia e da competição, com ênfase nos resultados, predominam nos rituais de escolha dos gestores escolares, e estes são impelidos a adotar os conceitos de mercado no planejamento da gestão escolar e na condução pedagógica para superação dos problemas educacionais, através dos instrumentos de controle de processos e de resultados. A reverberação desse processo finaliza na materialização da valorização dos estudantes que apresentem os melhores desempenhos com base nos indicadores educacionais estabelecidos pelo sistema de ensino.

A segunda etapa do processo seletivo para a ocupação do cargo de diretor e vice-diretor na rede estadual baiana de ensino é a eleição. A normativa vigente determina que o voto é direto, secreto e facultativo, sendo proibido o voto por representação. São considerados eleitores, os estudantes a partir de 12 (doze) anos de idade com 
frequência regular, pais ou responsáveis, professores efetivos e contratados, coordenadores pedagógicos e demais servidores públicos, em efetivo exercício na unidade escolar, inclusive os contratados em caráter temporário sob o Regime Especial de Direito Administrativo - REDA (BAHIA, 2015).

O mandato dos gestores eleitos tem duração de 04 (quatro) anos e eles podem ser reconduzidos por mais de um mandato, através de um novo processo de seleção interno, para o mesmo cargo ou outro, na mesma unidade escolar (BAHIA, 2015).

Segundo Lima (2014, p. 1071), a eleição é "uma regra nuclear da democracia e nas escolas, também, um testemunho e uma prática com potencial impacto numa educação para e pela democracia". Nessa perspectiva, a eleição de gestores escolares é o processo que melhor materializa a luta contra o autoritarismo na gestão da educação.

Em alguns municípios brasileiros, a indicação política e o concurso público são formas de provimento para o exercício do cargo de gestor escolar. Nesse cenário, a colegialidade é fragilizada porque a comunidade não pode escolher ou opinar sobre modelo de gestão que será constituído no interior da escola, consequentemente, também não participará do processo de tomada de decisão.

Embora que, contraditoriamente, um gestor escolar eleito e legitimado pela comunidade, não significa a presença de democracia na escola, ou seja, não garante que as instâncias envolvidas no processo eletivo poderão participar dos processos decisórios. Para Aires (2018, p. 65), a "administração educacional praticada nas escolas reflete e assume as marcas, as contradições sociais e os interesses políticos em jogo na sociedade".

Portanto, no tocante ao princípio da gestão democrática, geralmente, ele é associado à escolha do dirigente escolar pela comunidade, através do processo eletivo. Entretanto, a prática democrática é um desafio rotineiro enfrentado no interior das escolas e nos sistemas educacionais deste país porque é axiomático que "não pode haver democracia plena sem pessoas democráticas para exercê-las" (PARO, 2016, p. 33).

\section{Colegiados escolares}

As políticas que se voltam para a democratização das relações escolares devem considerar o contexto da comunidade local em que elas se inserem, suas necessidades decorrentes e as condições objetivas em que elas se efetivam. O colegiado escolar é mais uma das ferramentas que concede à escola um caráter democrático, pois é através dele que se inicia o diálogo e a correlação entre a escola e a comunidade.

\footnotetext{
A participação democrática, ativa e convergente, exige amadurecimento para comprometer-se. O que significa discordar ou concordar priorizando o compartilhamento dos objetivos e metas, tornando-se corresponsável pelo desenvolvimento de ações voltadas, não para interesses pessoais ou grupais, mas para a melhoria dos indicadores escolares (SILVA, 2011, p.3).
}

Segundo Adrião e Camargo (2007), mesmo antes da Constituição de 1988, o conselho escolar era visto como um dos meios para a democratização das relações de poder no interior da escola, visto que é composto de representantes dos docentes, pessoal administrativo e de apoio da escola, estudantes e pais, eleitos por seus pares. O colegiado escolar tem atribuições consultivas, deliberativas e fiscais em questões que envolvem aspectos 
pedagógicos, administrativos e financeiros da escola. Essas atribuições são definidas por legislação estadual ou municipal e no regimento escolar.

Segundo o Ministério da Educação (MEC, 2004, p. 18),

[...] a complexidade da sociedade atual e o processo de democratização do público impuseram a ampliação dos mecanismos de gestão das políticas públicas, criando as políticas setoriais, com definição discutida em conselhos próprios, com abrangências variadas: unidades da federação, programas de governo, redes associativas populares e categorias institucionais.

Nessa perspectiva, a finalidade e a competência do colegiado nas unidades escolares estaduais baianas estão regulamentadas pela Lei n ${ }^{0} 11.043 / 2008$, publicada em maio de 2008. A legislação define que:

Art. $1^{0}$ - O Colegiado Escolar é órgão que garante a gestão democrática do ensino público, através da participação da comunidade escolar e local, na concepção, execução, controle, acompanhamento e avaliação dos processos administrativos e pedagógicos da ação educativa, no âmbito de cada unidade de educação básica do Sistema Estadual de Ensino.

Art. $2^{\circ}$ - A autonomia dos Colegiados se exercerá nos limites da legislação de ensino em vigor, das diretrizes da política educacional vigente expedidas pela Secretaria da Educação do Estado e do compromisso de serem centros permanentes de debates e órgãos articuladores dos setores escolar e comunitário (BAHIA, 2008, p. 1).

Na letra da lei, o colegiado escolar "configura-se como estratégia para assegurar a política pública de democratização da gestão da escola" (Silva, 2011, p. 1) e se estabelece como um centro permanente de debates com autonomia, nos limites da legislação vigente.

A normativa baiana estabelece que o colegiado escolar tem funções de caráter deliberativo, consultivo, avaliativo e mobilizador dos processos pedagógicos, administrativos e financeiros das unidades escolares. Em consonância, o inciso IX do Art. 24 do Estatuto do Magistério Público do Ensino Fundamental e Médio do Estado da Bahia, que trata das atribuições do diretor escolar, determina que este deve "assegurar a participação do colegiado escolar na elaboração e acompanhamento do plano de desenvolvimento da escola" (BAHIA, 2002, p.7).

Entretanto, observa-se que a gestão escolar é um espaço de poder que ainda é hierarquizado, controlado e centralizado na figura do gestor, com "encenações participativas" (LIMA, 2014, p. 1072) da comunidade no cotidiano da escola. A participação da comunidade escolar na gestão da escola pública ainda encontra dificuldades para sua concretização nas questões relacionadas à organização, funcionamento e ao desenvolvimento das atividades de ensino no seu interior.

Na ótica de Paro (2001, p. 80),

[...] o maior dos problemas existentes é o fato de que o conselho de escola tem sido tomado, em geral, como uma medida isolada, descolado de uma política mais ampla e séria de democratização da escola, evidenciando muito mais sua face burocrática do que sua inspiração democrática. Para a reversão desse quadro, é preciso uma nova ética que desautorize a atual configuração autoritária da escola. [...] o homem deve conduzir-se de forma dialógica com os demais homens, seus semelhantes, que, como ele, devem ter mantida sua condição de sujeito que, ao transcender a necessidade natural, constrói, pelo trabalho, sua própria liberdade.

Em agosto de 2008, o governo baiano publicou o Decreto $n^{\circ} 11.175 / 2008$, previsto na Lei ${ }^{\circ} 11.043 / 2008$, que dispõe sobre a implementação dos colegiados nas escolas públicas da educação básica do sistema estadual de ensino e define os critérios para composição do colegiado escolar. A escolha de membros será através de processo 
eletivo que é precedido de mobilização dos segmentos de toda comunidade escolar com realização de assembleias gerais (BAHIA, 2008).

Sobre a composição do colegiado escolar, o Decreto determina que podem concorrer aos cargos de representantes dos segmentos dos colegiados escolares, os estudantes matriculados na Unidade Escolar, a partir de 12 anos de idade, que apresentem frequência regular; professores e/ou coordenadores pedagógicos, em exercício na unidade escolar; servidores técnico-administrativos em exercício na unidade escolar; e pais e/ou responsáveis dos estudantes, devidamente matriculados, e com frequência regular.

No segmento de representantes da comunidade local podem ser eleitos membros de entidades como associações comunitárias, sindicatos, fundações, organizações não governamentais (ONG), organizações da sociedade civil de interesse público (OSCIP), instituições privadas e religiosas, cujos objetivos sejam vinculados às atividades educativas ou socioeducativas, com atuação na circunscrição da unidade escolar escolhida para candidatura. O mandato dos membros eleitos do colegiado Escolar tem duração de 02 (dois) anos (BAHIA, 2008).

De acordo com Bordenave (1992), essa articulação de forças é o exercício da colegialidade ou o compartilhamento das decisões com aqueles que dela fazem parte, buscando a superação da centralização e do autoritarismo da gestão escolar para cumprir a função social da escola como instituição pública que detém a obrigatoriedade de integrar e formar os cidadãos.

Em maio de 2019, o governo estadual publicou a Portaria de $\mathrm{n}^{\circ}$ 528/2019 que aprova as diretrizes, procedimentos e instrumentos para o processo de eleição, estruturação e o funcionamento do colegiado escolar nas unidades escolares da rede pública da educação básica estadual, para o biênio 2019/2021. Nesta portaria, o executivo, além de fazer chamada para realização de nova eleição para composição do colegiado escolar, define a disponibilidade de carga horária de professores, funcionários e estudantes para participação nas reuniões e atividades correlatas ao colegiado escolar. Ficando assim, determinado, no Art. $7^{\circ}$ :

\footnotetext{
I - os professores e coordenadores pedagógicos terão uma hora da atividade complementar semanal disponibilizada especificamente para este fim;

II - os funcionários terão horário especial de trabalho estruturado pelo Diretor da Unidade Escolar de forma a atender as demandas de suas atribuições no Colegiado;

III - os estudantes contarão com o apoio e liberação docente para participação nas reuniões do Colegiado Escolar, quando necessário, tendo sua atuação na gestão valorizada e articulada ao currículo escolar (BAHIA, 2019, p. 1).
}

A normatização da disponibilidade de carga horária para os servidores atuarem nas atividades do colegiado escolar, bem como, a manifestação de que a participação estudantil nessa instância democrática está articulada ao currículo escolar indicam avanços, considerando que na relação entre o Estado e a comunidade escolar existem marcas históricas de tensão, de tentativas de silenciamento. Na perspectiva de Silva (2011, p. 2), o colegiado, enquanto instrumento de participação, "é capaz de efetivar a política de democratização da gestão escolar, refletindo seu potencial como veículo de mudança de paradigmas e práticas gerenciais.”

\section{Contradições entre o marco legal e a Nova Gestão Pública}

A Nova Gestão Pública (NGP) é um programa que repousa sob a racionalidade técnica da Administração Pública. Dotada de princípios que remetem aos conceitos e práticas do ethos privado, a NGP advoga por uma 
política de resultados em detrimento do processo, fato que atinge diretamente a lógica da gestão democrática na educação e na escola.

Segundo Newman e Clarke (2012) a linguagem da NGP conseguiu impregnar apresentações governamentais, documentos sobre políticas e até mesmo manifestos de partidos políticos, além dos relatórios e diretrizes do Banco Mundial e outros órgãos. Nesse contexto, a legislação democrática baiana não ficou imune.

Os conceitos de "gerenciamento", "desempenho" e "controle" estão presentes nas atribuições do diretor escolar descritos no Art. 24 do Estatuto do Magistério do Magistério Público do Ensino Fundamental e Médio do Estado da Bahia (Bahia, 2002, p.7-8), bem como, os conceitos de "aferição", "competência", "habilidade", "meta" e "desempenho" constam nas etapas de seleção e de avaliação do trabalho do gestor escolar (BAHIA, 2015, p.1; 6-7).

Dando continuidade à incorporação e reprodução dos mecanismos da NGP no sistema estadual de ensino, o governo baiano, em dezembro de 2018, promulgou a Lei nº 14.032/2018, que trata da reorganização administrativa do Estado. Essa normativa modificou a estrutura organizacional da administração pública do poder executivo estadual e estabeleceu o regime de dedicação exclusiva para diretores e vice-diretores, em regime de tempo integral, sem alteração positiva na remuneração desses profissionais.

Essa decisão, em pleno findar de ano letivo, causou grande alvoroço nas unidades escolares, com exonerações de diretores e vice-diretores que tinham outros vínculos empregatícios. No Decreto no 16.385/2015 que regulamentou o último certame, não consta esse critério impeditivo para assunção ao cargo, mas os dirigentes escolares foram afastados, à revelia, da comunidade escolar e local, legitimando a crítica de que, no contexto da NGP, a escolha do diretor pela comunidade escolar e local e a constituição de colegiados não garantem, de fato, a autonomia escolar.

Essa ação, por parte do executivo, indica que:

\footnotetext{
A fragilidade das instituições democráticas reside na necessidade de uma unidade entre a ação e a palavra que deve ser constantemente reposta. Todo divórcio entre a ação e a palavra, ou ainda entre a "Constituição" e a "ação política" conduz a uma situação onde a palavra torna-se surda, a "Constituição" supérflua e a ação violenta (ROSENFIELD, 1988, p. 45).
}

Numa gestão escolar, de perspectiva democrática, a autonomia escolar, ou seja, a capacidade de decisão sobre o projeto educacional a partir do contexto social e cultural e das particularidades da escola é elemento fundante. Aires (2018, p. 66), define autonomia como "princípio constitutivo da democracia". No entanto, para Verger e Normand (2015), contraditoriamente, a autonomia escolar ocupa um lugar central nos instrumentos da política educacional da NGP e é globalmente aceita como válida porque fornece legitimidade à mudança educacional.

A NGP impõe a subordinação do gestor e dos professores a formas intensificadas de poder e controle centralizado do Estado que operam através da responsabilização, de regimes de desempenho, de diretrizes políticas para avaliação de competências e habilidades. Essas diretrizes políticas têm imposto uma regulação centrada na avaliação externa como parâmetro para medir a eficiência da gestão escolar: 
a educação como um mecanismo de promoção de justiça social por meio da distribuição de bens culturais e das possibilidades dadas aos indivíduos de se mobilizarem socialmente, a procura pelo sistema escolar passou a ser uma constante na luta pela ampliação dos direitos sociais nos últimos dois séculos. Contudo, ao adotarem os sistemas de avaliação como parâmetro das políticas educacionais, definindo em alguns casos até mesmo a distribuição e destinação dos recursos públicos, os governos acabam por legitimar suas escolhas político-ideológicas por meio da racionalidade técnica (OLIVEIRA, 2015, p. 640).

Nesse panorama, analisaremos as diretrizes políticas de avaliação adotadas pelo sistema de ensino estadual baiano. Para a consecução desse intento, utilizou-se o sítio eletrônico da Secretaria de Educação da Bahia (SEC/BA), como fonte de informações, onde se verificou que, no ano em curso, foi implementado o Sistema de Avaliação Baiano de Educação (SABE) com o "objetivo de fortalecer o processo avaliativo nas unidades escolares, identificando indicadores pedagógicos que subsidiem a atuação da SEC e das escolas nos processos de aprendizagens dos estudantes" (SEC/BA, 2019).

Conforme descrito no sítio, em 2019, o SABE disponibilizou às escolas, os seguintes instrumentos avaliativos:

1. Avaliação Diagnóstica - Identifica alguns conteúdos e habilidades que já foram desenvolvidos pelos estudantes, bem como os objetos do conhecimento que precisam ser fortalecidos.

2. Atividade de Apoio ao Estudante - Exercícios que visam fortalecer as aprendizagens dos estudantes, considerando os dados obtidos no Sistema de Avaliação Baiano de Educação.

3. Avaliação Formativa - Pretende apresentar mais informações que possam subsidiar a adoção de novas estratégias pelos professores para potencializar as aprendizagens dos estudantes. Nesta avaliação, professores e estudantes devem refletir sobre o esforço e envolvimento de cada um para aperfeiçoar o processo de ensino e de aprendizagem.

4. Prova SABE - Avaliação externa, com a mesma metodologia das avaliações do Saeb, que tem por finalidade aproximar os estudantes dos procedimentos exigidos em diversas avaliações usadas nacionalmente e subsidiar as escolas com informações sobre a evolução das aprendizagens dos estudantes, por meio de instrumentos calibrados, para melhoria dos processos de ensino e das aprendizagens (SEC, 2019, p. 1).

Segundo informações desse site, a atividade diagnóstica foi disponibilizada às unidades estaduais de ensino em março e, conforme cronograma divulgado, os estudantes baianos da capital e do interior, no mês de setembro, realizaram a prova SABE.

Nesse cenário, a avaliação da aprendizagem tem sido alardeada como elemento basilar para a promoção e garantia da educação de qualidade. A avaliação em larga escala passou a constituir-se em mecanismo central de regulação, fornecendo indicadores que são utilizados nos estabelecimentos de metas de gestão e na definição dos currículos.

Dessa forma, o modelo gerencialista para a condução dos rumos da educação, trouxe intensificação nas atribuições do gestor escolar, uma vez que, recai sobre ele o protagonismo para implementação dessa política de avaliação por resultados na escola, disseminando entre os professores, estudantes e pais, a ideia ilusória de que essa política trará "qualificação" para o processo de ensino e de aprendizagem.

A política de avaliação por resultados, inevitavelmente, provoca interferência na organização e gestão da educação e "um consequente distanciamento da ideia de escolarização como um meio de reparar padrões estruturais de injustiça social" (NEWMAN; CLARKE, 2012, p. 367).

Paro (2016) considera que o Estado se faz mais visível e contundente em sua pressão sobre a escola e na maneira burocratizada com que se relaciona com a unidade escolar. O elemento mais notável dessa burocratização é o acúmulo de trabalho que ela acarreta à gestão escolar. 
Observa-se que os (as) diretores (as) atuam no limite da relação entre os recursos disponíveis e as condições objetivas para a oferta educacional, especialmente em unidades escolares que apresentam condições estruturais precárias, localizadas em regiões de vulnerabilidade social (OLIVEIRA; DUARTE; CLEMENTINO, 2017, p. 716)

Destarte, o trabalho docente também sofre maior exploração. Oliveira (2007, p. 369) faz uma análise situacional dessa questão:

\begin{abstract}
Ao mesmo tempo em que ganham mais autonomia, liberdade de definir certas regras do seu diaa-dia, como o calendário, a escolha de um tema transversal que deverá ser trabalhado por toda a escola, definir projetos, discutir coletivamente saídas e estratégias para desafios encontrados localmente $[\ldots]$ os trabalhadores docentes se tornam mais presos às suas atividades e compromissos. A responsabilização sobre os destinos da escola, dos alunos, dos projetos passa a ser cada vez maior. É como se os trabalhadores docentes tivessem que pagar um preço por esta autonomia conquistada, já que é resultante de suas lutas.
\end{abstract}

Assim, seguindo os princípios da NGP, os resultados da avaliação de aprendizagem tornaram-se o principal objetivo político educacional e com status de sinônimo de qualidade da educação.

Segundo constatação de Oliveira (2015, p. 641),

Em meio à busca de resultados, vai se perdendo no processo a construção histórica da educação como um bem público, um direito social e que, como tal, não pode ser regulada como mercadoria, produto ou resultado passível de mensuração entregue a especialistas em medição e números.

Nesse sentido, em que pese a educação baiana contar com marcos legais considerados avançados para democratização das unidades escolares, contraditoriamente, os princípios e práticas adotadas a partir do referencial político e epistemológico da NGP, acabam por comprometer iniciativas que busquem dar materialidade ao que está subscrito no marco legal.

\title{
Considerações finais
}

A gestão escolar adquiriu centralidade no processo de redemocratização brasileira. A reflexão sobre a gestão escolar e sua efetiva democratização exige que se leve em consideração os desafios do cotidiano escolar, o momento político atual e a necessidade de garantir os processos institucionais e democráticos de ensino e de gestão.

A meta 19 do PNE fixou prazo de 02 (dois) anos para que os estados e os municípios assegurassem a gestão democrática em todas as escolas públicas da educação básica, com recursos da União. Entretanto, o prazo já venceu sem que a meta tenha sido atingida, status não diferente das outras metas do PNE.

A escolha do gestor escolar pela comunidade onde a escola está inserida, ainda não é realidade, na maioria dos municípios brasileiros. Segundo Souza e Pires (2018), do conjunto de 27 Unidades Federativas, apenas 11(onze) estados da federação e o Distrito Federal possuem leis próprias de gestão democrática, regulamentando o artigo 206 da CF e o artigo 14 da LDB, isto quer dizer que, apenas 44,4\% das UF o fizeram.

No tocante ao funcionamento dos colegiados, destaca-se que eles, se atuantes, possibilitam a maior participação da comunidade escolar na tomada de decisões que podem interferir na gestão da escola, por serem constituídos por representantes da comunidade local e dos profissionais de educação que também são responsáveis 
pela implementação e avaliação do Projeto Político-Pedagógico (PPP) que é o documento orientador das perspectivas filosóficas e pedagógicas da escola, dos seus aspectos estruturantes, da organização e gestão escolar e das suas intencionalidades.

A normatização e a atuação das instâncias participativas são indicadores das condições e do ambiente democrático no interior de uma escola, ao tempo em que os processos de participação são estratégias de aprendizagem do poder em todos os espaços de atuação, seja em reuniões, assembleias, planejamentos comunitários, votações, visto que, "a garantia da gestão democrática, com a participação mais efetiva da sociedade civil, depende desse aprendizado" (AIRES, 2018, p.71).

Entretanto, a presença da racionalidade técnica no sistema de educação causa tensões e incertezas no ambiente escolar quando o Estado, referenciado pelos parâmetros da NGP, em nome da qualidade educacional, estimula a competição entre escolas por financiamento, por alunos "mais capazes", por sucesso em avaliações de desempenho, sobrecarregando, dessa maneira, o trabalho do gestor escolar e dos professores, como mecanismo de escamotear o processo de deterioração das atividades fins da escola.

Nesse contexto, como resultado dessa pesquisa, consideramos que, na perspectiva da política de gestão democrática, a legislação baiana apresenta avanços e legitima a participação da comunidade escolar e local nas discussões e deliberações no interior da escola, através das leis e decretos supracitados que normatizaram a escolha dos dirigentes escolares e a implantação de colegiados escolares. Porém, constatamos que a NGP se apresenta como um entrave para democratização da educação e da escola.

O marco legal é imprescindível, contudo, as ações permanentes de fortalecimento das instâncias que norteiam e asseguram a política de gestão democrática nas escolas através da participação coletiva são elementos fundamentais para superar os entraves oriundos da lógica e dos princípios da NGP presentes nas reformas e diligências educativas das esferas públicas.

\section{Referências}

ADRIÃO T.; CAMARGO, B. R. A gestão democrática na Constituição Federal de 1988. In: OLIVEIRA, R.; ADRIÃO, T. Gestão, financiamento e Direito à Educação. 3. ed. São Paulo: Xamã, 2007.

AIRES, C. J. Programas governamentais - Contradições no processo de implementação da gestão democrática e o impacto no trabalho do diretor de escola. In: PEREIRA R. S.; SILVA, M. A. Gestão escolar e o trabalho do diretor. Curitiba: Appris, 2018.

ALVES, A.G. R. A gestão da educação na política educacional do estado de Mato Grosso do Sul: Análise da proposta de "educação para o sucesso" (2007-2013). In: REUNIÃO NACIONAL DA ANPED. 37., 2015. Anais [...]. UFSC - Florianópolis, 2015.

BRASIL. Constituição, 1988. Constituição Federal. São Paulo: Lex, 1988. 
BRASIL. Lei no 9.394, de 20 de dezembro de 1996. Estabelece as diretrizes e bases da educação nacional. Disponível em: http://www.planalto.gov.br/ccivil_03/LEIS/19394.htm. Acesso em: 29 jan. 2018.

BRASIL. Lei no 13.005, de 26 de junho de 2014. Aprova o Plano Nacional de Educação (PNE). Disponível em: http://www.planalto.gov.br/ccivil_03/_ato2011-2014/2014/lei/113005.htm. Acesso em: 29 jan. 2018.

BAHIA. Lei n⿳亠丷 8.261 de 29 de maio de 2002. Dispõe sobre o Estatuto do Magistério Público do Ensino Fundamental e Médio do Estado da Bahia.

BAHIA. Lei n⿳ ${ }^{0} 11.043$, de 09 de maio de 2008. Dispõe sobre a finalidade, competência e composição do Colegiado Escolar nas escolas públicas de Educação Básica do Sistema Estadual de Ensino.

BAHIA. Decreto $\mathbf{n}^{0} \mathbf{1 1 . 1 7 5}$, de 18 de agosto de 2008. Dispõe sobre a implementação dos Colegiados Escolares, nas Escolas Públicas da Educação Básica do Sistema Estadual de Ensino.

BAHIA. Decreto $\mathbf{n}^{\mathbf{0}} \mathbf{1 6 . 3 8 5}$, de 26 de outubro de 2015. Dispõe sobre os critérios e procedimentos do processo seletivo interno a ser realizado pela unidade escolar, requisitos para o preenchimento dos cargos de Diretor e Vice-Diretor das unidades escolares estaduais.

BAHIA. Lei $\mathbf{n}^{\circ}$ 14.032, de 18 de dezembro de 2018. Modifica a estrutura organizacional da Administração Pública do Poder Executivo Estadual.

BAHIA. Portaria $\mathbf{n}^{\mathbf{0}}$ 528, de 10 de maio de 2019. Aprova as diretrizes, procedimentos e instrumentos para o processo de eleição e o funcionamento do Colegiado Escolar para o Biênio 2019/2021.

BORDENAVE, J.E. D. O que é participação? 7. ed. São Paulo: Brasiliense, 1992.

DOURADO, L.F. Gestão da educação escolar. Brasília: Universidade de Brasília, Centro de Educação a Distância, 2006.

CURY, C.R.J. Gestão democrática dos sistemas públicos de ensino. In: OLIVEIRA, M. A.M. Gestão Educacional: novos olhares, novas abordagens. Petrópolis: Vozes, 2005.

CURY, C.R.J.; HORTA, J.S.B.; BRITO, V.L. A. Medo à Liberdade e Compromisso Democrático: LDB e Plano Nacional da Educação. São Paulo: Editora do Brasil, 1997.

INEP. Instituto Nacional de Estudos e Pesquisas Educacionais Anísio Teixeira. Dados. Disponível em: http://portal.inep.gov.br/web/guest/dados. Acesso em: 27 set. 2019.

LIMA, L. C. A gestão democrática das escolas: do autogoverno à ascensão de uma pós-democracia gestionária? Educ. Soc., Campinas, v. 35, n. 129, p. 1067-1083, out./dez., 2014.

MEC. Ministério da Educação. Programa Nacional de Fortalecimento dos Conselhos Escolares. Conselhos Escolares: uma estratégia de gestão democrática da educação pública. Brasil: 2004.

MENDONCA, Erasto Fortes. Estado patrimonial e gestão democrática do ensino público no Brasil. 
Educ. Soc., Campinas, v. 22, n. 75, p. 84-108, ago. 2001. Disponível em: http://www.scielo.br/scielo. php?script=sci_arttext\&pid=S0101-73302001000200007\&lng=en\&nrm=iso. Acesso em: 20 out. 2019.

NEWMAN, J.; CLARKE, J. Gerencialismo. Educ. Real, Porto Alegre, v. 37, n. 2, p. 353-381, maio/ ago. 2012. Disponível em: http://www.ufrgs.br/edu_realidade. Acesso em: 20 out. 2019.

OLIVEIRA, D. A. Nova. Gestão Pública e governos democrático-populares: contradições entre a busca da eficiência e a ampliação do direito à educação. Educ. Soc. Campinas, v. 36, n. 132, p. 625 646, jul.-set, 2015.

OLIVEIRA, D. A.; DUARTE, A. W. B.; CLEMENTINO, A. M. A Nova Gestão Pública no contexto escolar e os dilemas dos (as) diretores (as). RBPAE, v. 33, n. 3, p. 707 - 726, set./dez. 2017.

OLIVEIRA, J.F. Gestão escolar democrática: definições, princípios e mecanismos de implementação. Séries políticas e Gestão na educação. Brasília: MEC/Inep, 2007.

PARO, V. H. Por dentro da escola pública. 4. ed. São Paulo: Cortez, 2016.

PARO, V. H.. Escritos sobre educação. São Paulo: Xamã, 2001.

PERONI, V. M. V; FLORES, M.L.R. Sistema nacional, plano nacional e gestão democrática da educação no Brasil: articulações e tensões. Educação (Porto Alegre, impresso), v. 37, n. 2, p. 180-189, maio-ago. 2014.

ROSENFIELD, Denis L. O que é democracia. São Paulo: Nova Cultural. Coleção Primeiros Passos, 1988.

SEC. Secretaria de Educação do Estado da Bahia. Sistema de Avaliação Baiano de Educação SABE. Disponível em: http://escolas.educacao.ba.gov.br/sabe. Acesso em: 26 set. 2019.

SILVA, A. L. Gestão democrática: A ação do colegiado escolar como estratégia de democratização da gestão. In: SIMPÓSIO BRASILEIRO DE POLÍTICA E ADMINISTRAÇÃO DA EDUCAÇÃO, 25., 2011, São Paulo. Anais [...]. São Paulo: PUC, 2011. Disponível em: http://www.anpae.org.br/ simposio2011/cdrom2011/PDFs/trabalhosCompletos/comunicacoesRelatos/0055.pdf. Acesso em: 06 out. 2019.

SOUZA, Â. R.; PIRES, P. A. G. As leis de gestão democrática da Educação nos estados brasileiros. Educar em Revista, Curitiba, Brasil, v. 34, n. 68, p. 65-87, mar./abr. 2018.

SOUZA, Â. R. Explorando e construindo um conceito de gestão democrática. Educação em Revista, Belo Horizonte, v. 25, n. 3, p. 123-140, dez. 2009.

VERGER, A.; NORMAND, R. Nueva Gestión Pública y educación: elementos teóricos y conceptuales para el estudio de un modelo de reforma educativa global. Educ. Soc., Campinas, v. 36, n. 132, p. 599-622, jul.-set. 2015. 